\title{
Research on Collaborative Governance of Multiple Subjects of Air Pollution in Heilongjiang Province
}

\author{
Qing Zheng ${ }^{1}$, Ning Shi $^{2}$, Xiaoyu Liu ${ }^{3}$ \\ ${ }^{1}$ Harbin Finance University, department of finance, Harbin, Heilongiiang, China \\ ${ }^{2}$ Harbin Finance University, department of finance, Harbin, Heilongjiang, China \\ ${ }^{3}$ Harbin Finance University, department of finance, Harbin, Heilongjiang, China
}

\begin{abstract}
In recent years, The economy of Heilongjiang province has developed rapidly, but the problem of air pollution, especially the haze in winter, is serious. In order to improve the ecological environment quality of Longjiang and promote high-quality economic development, the Heilongjiang provincial government has taken a series of key measures to prevent and control air pollution, and the air environment quality has been continuously improved. The prevention and control of air pollution requires the joint efforts of the government, enterprises and the public in order to win the battle against air pollution.
\end{abstract}

\section{Introduction}

Building an ecological civilization is a millennium project for the sustainable development of the Chinese nation. While developing the economy, we should also pay attention to environmental protection and support the development of green economy. Under the background of China's rapid economic development, Heilongjiang province's economic development tends to be better. Environmental protection has also become the key to the sustainable economic development of Heilongjiang Province. Due to the longer heating time in winter, the haze is more serious in winter, and the emission of industrial enterprises and straw burning also aggravate the air pollution. In order to effectively control air pollution, we should take the government as the leader, enterprises as the main body, social organizations and the public to participate in the joint efforts of multiple subjects to control air pollution. We will fully implement Xi Jinping thought on ecological progress and resolutely win the battle for blue skies.

\section{The main source of air pollution in Heilongjiang Province}

In 2019, the average annual concentration of PM2.5 in Heilongjiang was 28 micrograms per cubic meter, the same as last year, ranking 7th in China. The number of good days was 93.3 percent, up 0.2 percentage points, ranking 8th in China. The main sources of air pollution are coal burning, industrial pollution, straw burning and automobile exhaust pollution.

\subsection{Automobile exhaust}

Automobile exhaust is one of the important causes of air pollution and haze weather. According to the National Bureau of Statistics, 253.87 million civilian cars and 225.13 million private cars were owned in 2019.

The number of private cars in Heilongjiang Province is increasing year by year. Although the increasing number of cars brings great convenience to people's life, it also causes very serious automobile exhaust pollution.

\subsection{Heating in winter}

Heilongjiang province winter heating time is long, from October to the next Year in April. In winter, a large amount of energy is needed for heating, so coal becomes the first choice. The large amount of coal is used, which leads to air pollution and severe smog in winter. According to the 2019 Ecological environment bulletin of Heilongjiang Province, the average number of good days in 2019 is $89.6 \%$ in the heating period (January 1-April 15 and October 15December 31), and $97.1 \%$ in the non-heating period (April 16 -October 14). Heating in winter has a great influence on air quality in Heilongjiang Province.

\subsection{Industrial enterprise emission}

The production of industrial enterprises, such as steel, cement, coal, sewage treatment works, waste incineration plant, etc. can cause quite serious environmental pollution problems, and the air pollution caused by enterprise waste gas emissions is an important source of air pollution. The prevention and control of air pollution not only requires government supervision, but also requires enterprises to take the initiative, strengthen enterprise self-discipline,

\footnotetext{
*Corresponding author: zhengqingq0611@163.com
} 
carry out continuous technological innovation and reduce pollution emissions.

\subsection{Straw burning}

Straw burning causes haze weather, traffic accidents, fires, damage the soil structure, and produces a large number of toxic and harmful substances, which is a threat to human and other biological health. In order to strictly control the straw burning, Heilongjiang issued the Interim Provisions on Rewards and Punishments for Banning the open-air burning of straw in Heilongjiang Province. It promotes a grid supervision system at the municipal, county, township and village levels. Those responsible for the illegal burning of straw are strictly investigated and punished.

\subsection{Dust}

"Dust" pollution is very harmful to the ecological environment and human health, which is one of the main sources of air pollutant PM10. With the continuous acceleration of urbanization in Heilongjiang Province, dust pollution at construction sites, exposed land and other construction sites has a wide distribution and large area, and there are certain blind areas only by manual inspection. The main sources of dust pollution are exposed ground, dust from yard, building construction, road and pipeline construction, etc.

\section{Problems in the prevention and control of air pollution}

In 2019, 11 out of 13 prefecture-level and above cities in Heilongjiang province met the air quality standards, except two cities, Harbin and Suihua. The 13 cities in the province had a total of 4,417 good days and 317 polluted days, among which 69 were heavily polluted days or above. The problem of air pollution in Heilongjiang province is still serious, and there are still many challenges in the process of air pollution control.

\subsection{Imperfect laws and regulations}

China's laws on air pollution control include The Constitution, The Environmental Protection Law, The Air Pollution Prevention and Control Law, The Energy Conservation Law, and The Clean Production Promotion Law, but their enforceability is still not high. In recent years, Heilongjiang province has also issued The Regulations on Prevention and Control of Air Pollution in Heilongjiang Province, but there are too many provisions and lack of flexibility. Many environmental law enforcement departments are subject to the financial pressure of the government, and their autonomy cannot be brought into play. Their law enforcement team are not enough, and their law enforcement efforts are not enough. Imperfect legislation and weak law enforcement have led to the great challenge of local air pollution control.

\subsection{The enterprise is not punished enough for breaking the law}

Pollution has negative externality. The emission of pollution by an enterprise causes losses to others and the environment, but the enterprise itself does not need to bear such "external cost", resulting in the marginal cost of society greater than the marginal cost of individuals. The pursuit of profit maximization will inevitably give up social benefits to some extent. At present, the cost of breaking the law is low and the punishment is not enough. Some enterprises feel that the cost of abiding by the law is higher than the cost of breaking the law, so they have to continue their production and operation even at the risk of breaking the law for economic benefits. First, the government should intervene to solve the negative externalities of enterprise pollution emission, raise the cost of enterprise violation and strengthen the punishment. Second, enterprises also need to improve the sense of selfdiscipline.

\subsection{Low public participation}

The environmental protection in Heilongjiang province is led by the government. In some areas, the environmental pollution information is not transparent, the public's awareness of environmental protection is not strong, and there are few ways to participate in air pollution control, with low enthusiasm and participation. It is difficult for the public to play their supervisory role in environmental protection and prevention. The prevention and control of air pollution is complex, it cannot only rely on governments and enterprises, but must rely on the efforts of the general public to succeed.

\subsection{It is difficult to carry out responsibility for air pollution}

Because the air is fluid, air pollution control responsibility is difficult to determine. If the distribution of responsibilities to their respective jurisdictions is not conducive to the overall governance of air pollution, the governance of air pollution requires cross-regional coordination, joint prevention and control. In some areas, there is a phenomenon of "free riding" in pollution control, which makes it difficult to achieve the effect of pollution control.

\section{Measures for the coordinated prevention and control of air pollution by multiple entities}

\subsection{The balance between multiple subjects in pollution prevention and control}

Governments, enterprises, social organizations and the public all play a very important role in preventing and controlling pollution. The report of the 19th National Congress of the Communist Party of China made it clear that we should build an environmental governance system 
in which the government is the leader, enterprises is the main body, and the public take part. In the prevention and control of air pollution, there are mutual checks and balances between the government and enterprises, between the government and the public, and between enterprises and the public.

\subsubsection{Government and business}

In the relationship between multiple subjects of pollution prevention and control, the government takes the lead and the enterprise is the main body. The interests of government and enterprise are interrelated and affect each other. Government environmental regulation will affect the production and operation of enterprises, which in turn will affect the tax revenue of the government due to the impact of government environmental regulation, thus affecting the environmental investment or environmental regulation behavior of the government. First, the government strictly controls the emission of pollution, which will lead to the outflow of enterprises and labor force. Second, the outflow of enterprises and labor force will react on the intensity of environmental regulation by the government.

\subsubsection{Government and the public}

The relationship between the government and social organizations and the public also exists. First, the environmental protection and governance behaviors of the government affect the public, such as the mobility of labor force, and people will choose to live and work in cities with good environment. Second, the public express their demands for the environment through "voting with their hands" and "voting with their feet" (labor loss), which will affect the government's reputation and fiscal revenue, thus affecting the government's environmental protection and governance behavior.

\subsubsection{Enterprises and the public}

Environmental pollution will lead to the loss of labor, and the loss of labor will affect the long-term development of enterprises. Therefore, social organizations and the public "vote with their feet" is also a threat to enterprises. This "threat" could prompt companies to cut emissions, the wage level of the enterprise will also have an impact on labor mobility.

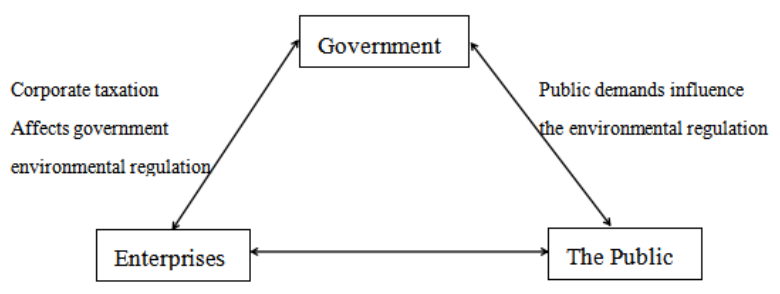

Labor mobility affects enterprise development

Fig. 1. The relationship between the government, enterprises and the public in the coordinated governance of air pollution

\subsection{Measures for the coordinated prevention and control of air pollution}

\subsubsection{Strengthen government supervision}

The Heilongjiang local government should strengthen the supervision and management of air pollution, keep an eye on the air quality prediction, the implementation of emergency response measures, and the pollution sources around heavily polluted area, and strictly investigate the pollution in key areas, in key periods, and in key industries. The government should improve rules and regulations, strengthen principal responsibility, improve coordination among government departments, refine and break down tasks and objectives, strictly supervise and enforce laws, increase assessment and accountability to ensure that all prevention and control tasks are carried out in place. Specifically, air pollution can be prevented from the following aspects:

First, we will control pollution caused by burning coal, accelerate the development of clean energy, promote clean heating, and replace coal with natural gas and power. Second, we will comprehensively deal with industrial pollution, optimize and adjust the industrial structure, strictly control the production capacity of industries with "two high levels", strengthen governance of enterprises with "disorderly and polluted" industries, and increase efforts to cultivate green and environmental protection industries. Third, we should ban straw burning, strictly implement the control mechanism of straw burning, formulate and implement the reward and punishment mechanism, and promote the ban of straw burning in all regions and all periods. Fourth, strict control and inspections should be carried out in the transport sector to eliminate highly polluting motor vehicles, motor vehicles and non-road mobile machinery to meet environmental standards. Fifth, strict control of road dust, demolition and construction dust, garbage classification management, urban greening construction should be strengthen.

\subsubsection{Strengthen enterprise self-discipline to achieve cleaner production}

Enterprises are the main body of air pollution prevention and control, which produce a large amount of industrial waste gas. The prevention and control of air pollution requires enterprises to strengthen self-discipline, eliminate the processes, equipment and products that seriously pollute the air environment, and make use of clean energy and green energy to carry out clean production. In order to promote industrial agglomeration, the government should rationally plan the layout of industrial parks, build heat sources and heat grids in industrial parks, and reduce exhaust emissions. Enterprises produce and use nonvolatile raw materials and products containing low toxicity and low volatile organic compounds. The activities of enterprises producing waste gas containing volatile organic compounds (such as coal processing, petrochemical production, etc.) shall be carried out in closed Spaces or equipment in accordance with state regulations, and pollution prevention and control facilities 
shall be installed and used in accordance with relevant regulations. Measures shall be taken to reduce waste gas emissions if such facilities cannot be sealed. Petrochemical and other industrial enterprises shall adopt leak detection and repair technology, carry out daily detection and repair of pipelines and equipment, and timely collect and deal with leaking materials. The garbage classification system should be generally implemented to recover and utilize the combustible gas generated during landfill, and to prevent pollution if the landfill does not have the conditions for recovery and utilization.

\subsubsection{Raise public awareness of environmental protection}

The public can choose buy energy-saving and new energy vehicles in line with national standards, also can choose public transport, taxi, commuter car, or bicycle or hiking to reduce exhaust emissions. Choose low-carbon travel or a carbon-free trip, reduce the use of disposable items.

Straw burning is an important source of air pollution. The public should actively cooperate with the government and abide by the prohibition of open burning of straw in areas where open burning is prohibited. The straw was returned to the field by means of crushing and fertilizing. Poultry farms and breeding plots shall collect, store, clean and transport livestock and poultry feces and dead bodies in a timely manner and in a concentrated manner so as to prevent the discharge of malodorous gases.

The government, enterprises and the public should make joint efforts to strengthen the publicity of garbage classification and raise the public's awareness of garbage classification. The public should cooperate with the government to do a good job of garbage classification. Simple dumping or landfills can spread the stench and contaminate the soil, groundwater and air. Garbage classification can effectively recycle resources, reduce waste incineration, and reduce air pollution.

The prevention and control of pollution requires the joint participation of the government, enterprises, and the public. The supervision of environmental pollution by the public should be strengthened. Social organizations and the public "vote with their hands" and "vote with their feet" will promote the optimization of local ecological environment. The government needs to strengthen the disclosure of environmental information, mobilize the whole society to participate widely, and carry out publicity and education on environmental protection and air pollution prevention and control among the masses. The public can respond to environmental pollution problems through the mailbox of the director of the Department of Ecology and Environment of Heilongjiang Province, consultation message, online survey and other ways, put forward suggestions, or report through the 12369 reporting platform.

\section{Conclusion}

With the development of economy, the pressure of environmental pollution is increasing day by day.
However, environmental pollution caused by economic development is not inevitable. Ecological environment is the foundation of economic development. At the same time of economic development, attention should be paid to environmental protection to realize the coordinated development of economy and environment. The prevention and control of air pollution requires the cooperation of multiple subjects, and the contribution of their respective forces through reasonable institutional arrangements. We shoud firmly establish the concept that "clear water and green mountains are gold and silver mountains, and ice and snow are also gold and silver mountains", and promote green development to build a beautiful Heilongjiang.

\section{Acknowledgments}

This paper is one of the phased achievements of the 2019 Heilongjiang Provincial universities' key project of basic scientific research operating expenses, "Research on Economic Mechanism of Multi-Subject Co-Governance of Pollution from the Perspective of Green Development"(2019-KYYWF-012).

\section{References}

1. Tian, Y.Y., Wang, H., Zhang, R.W. (2020) Discussion on Collaborative Governance of Multiple Subjects of Rural Pollution in Hebei Province -- Based on the Perspective of Rural Revitalization. North China Economy and Trade, 04: 37-38.

2. Dong, K., Zhou, C.L. (2019) An Analysis of Accelerating the Legalization of Air Pollution Control in China -- A Case study of Harbin. Rural economics and science and technology, 06: 34+206.

3. Zhu, J.Y. (2018) Research on the Challenges and Countermeasures of air pollution Prevention and Control in the New Era. Low Carbon World, 04: 12-13.

4. Wang, T.T., Wang, L.Y. (2014) Review and improvement of China's air pollution prevention and control legal system. Resources and industry, 16: 32-36.

5. Huang, L.M. (2005) Public Participation in air Pollution Prevention and Control in China. Journal of Tianshui School of Administration, 03: 21-24. 